\title{
O DESEMPENHO EM INOVAÇÃO EM SISTEMAS COMPLEXOS DE ATUAÇÃO, APOIADO PELA EVOLUÇÃO E INTEGRAÇÃO ENTRE AS GESTÕES DA QUALIDADE E DO CONHECIMENTO
}

\author{
INNOVATION PERFORMANCE IN COMPLEX SYSTEMS SUPPORTED BY \\ EVOLUTION AND INTEGRATION BETWEEN THE \\ QUALITY AND KNOWLEDGE MANAGEMENT
}

Francisco José Martins - Francisco.martins2@fatec.sp.gov.br

Faculdade de Tecnologia de Taquaritinga (Fatec) - Taquaritinga - São Paulo - Brasil

DOI: 10.31510/infa.v17i1.820

\begin{abstract}
RESUMO
A consolidação e certificação dos sistemas de gestão da qualidade, com os benefícios esperados, apresenta muitos estudos sobre o tema, porém, um menor número de trabalhos relacionando-os com a integração necessária com a gestão do conhecimento e a análise do ambiente externo de atuação do negócio, visto como um sistema complexo e altamente dinâmico, assim como as mudanças necessárias com base nas novas tecnologias e a contribuição efetiva desses sistemas no desempenho em inovação para as organizações. Neste contexto, o objetivo deste trabalho foi o resgate de conceitos sobre a evolução dos sistemas de gestão da qualidade, a sua integração com a gestão do conhecimento e o desempenho esperado em inovação, justificado pela relevância do tema nos cenários atual e futuro, que apresentam um desafio maior para os respectivos gestores nas organizações quanto à sua abrangência em ambientes cada vez mais dinâmicos e competitivos. Concluiu-se que a melhoria contínua e a integração dos processos de gestão, devidamente suportados pelas lideranças, deve fomentar também o desempenho inovador, devendo estar no foco de atenção dos gestores envolvidos, notadamente em pequenas e médias empresas em desenvolvimento, como fator de sobrevivência e crescimento.
\end{abstract}

Palavras-chave: Gestão da Qualidade. Gestão do Conhecimento. Inovação.

\begin{abstract}
The consolidation and certification of quality management systems, with the expected benefits, presents many studies on the theme, however, a smaller number of works relating them to the necessary integration with knowledge management and the analysis of the external operating environment of the business, seen as a complex and highly dynamic system, as well as the necessary changes based on new technologies and the effective contribution of these systems in innovation performance for organizations. In this context, the objective of this work was to rescue concepts about the evolution of quality management systems and their integration with knowledge management and the expected performance in innovation, justified by the relevance of the theme in the current and future scenarios, which presents a greater challenge for the
\end{abstract}


managers in the organizations, as well as their scope in increasingly dynamic environments. It is concluded that the continuous improvement and integration of the management processes, duly supported by the leaders, should also foster innovative performance, and should be the focus of attention of the managers involved, especially in the developing small and mediumsized companies, as a factor of survival and growth.

Keywords: Quality Management. Knowledge Management. Innovation.

\section{INTRODUÇÃO}

As organizações estruturam as suas práticas em Gestão da Qualidade (GQ), acumulando um histórico de experiências de sucessos e insucessos revertidos em aprendizados. Os sistemas de garantia da qualidade, apoiados nas normas da série ISO 9000, também ajudaram muitas organizações que optaram por sua implantação, na estruturação das suas gestões, procedimentos e cultura interna voltada para a qualidade. Novas tecnologias e a evolução dos sistemas de informação trouxeram novos subsídios para a GQ, aproximando-a ainda mais de conceitos e práticas em Gestão do Conhecimento (GC). Para as organizações, a integração da GC com as demais gestões internas, não somente a da qualidade, permite o melhor uso e ampliação do conhecimento adquirido, suporte para atuar em inovações, expandindo para resultados melhores e sustentáveis, fator de diferenciação e sobrevivência em seus respectivos mercados.

No que se refere a evolução das organizações, a maturidade de uma organização e de seus sistemas internos de gestão não se associam, necessariamente, ao tamanho da organização. Porém, a forma como a organização está estruturada em pessoas e recursos, associada ao seu estágio de desenvolvimento, pode apresentar características comuns a esses estágios no que se refere às práticas em GQ e GC.

Neste contexto, este trabalho tem por objetivo resgatar conceitos e tendências avaliadas nas últimas décadas em GQ, relacionando-os com a evolução e integração esperada com a GC em diferentes estágios do desenvolvimento organizacional e tecnologias aplicadas, contextualizando a relevância e oportunidade do tema nos cenários atual e futuro para com o desempenho em inovação. Buscou-se também um destaque maior para o suporte de empresas iniciantes e pequenas ou médias em desenvolvimento, indicando as possíveis dificuldades e etapas de evolução, nas quais os seus respectivos gestores possuem um forte desafio de atuação para com fatores de sucesso. 


\section{PROCEDIMENTO METODOLÓGICO}

Para atender ao objetivo proposto deste trabalho, considerou-se uma pesquisa bibliográfica relacionada ao tema, resgatando conceitos e visões verificados em trabalhos e

publicações a partir da década de 90, quando se iniciou a implantação e certificação de sistemas de gestão da qualidade apoiados nas normas da série ISO 9000, analisando e comentando a evolução desses conceitos para com as novas realidades de mercado e tecnologias no momento atual, assim como para com tendências futuras.

\section{REFERENCIAL TEÓRICO}

Há inúmeros trabalhos sobre GQ e GC, onde são identificadas características, associadas tanto às grandes como às pequenas e médias organizações, de modo similar ou com certas distinções, as quais permitem uma visualização geral sobre a forma e a abrangência da gestão praticada.

Garvin (2002), ao se referir às possíveis diferentes interpretações para o termo "qualidade", afirma que "é essencial um melhor entendimento do termo para que a qualidade possa assumir um papel estratégico", contribuindo assim para o negócio e sua evolução.

De um modo geral, as vertentes que conceituam tecnicamente o termo "qualidade" no meio organizacional se direcionam ao ponto de vista de que o produto, ou serviço, deve satisfazer ao cliente e/ou seu propósito principal, no que se refere à "percepção" quanto ao desempenho, durabilidade, confiabilidade, estética, preços compatíveis, serviços associados (atendimento, condições e prazo de entrega, assistência pós-venda), entre outros.

Os programas ou sistemas de garantia da qualidade, limitados a documentação e procedimentos para dar suporte às atividades operacionais, são úteis quando utilizados para informações e registros, mas podem não corresponder a uma cultura ou processos operacionais com relevância para a evolução da organização. A gestão da qualidade independe do tamanho da organização, porém, a sua efetiva implementação e sustentação pode apresentar certas dificuldades em função de aspectos relacionados, por exemplo, à disponibilidade de recursos, à estrutura e maturidade administrativa existente, à capacitação das pessoas, entre outras. 
Diferenças de ordem estrutural e de cultura interna podem ser verificadas entre as organizações, sejam estas pequenas, médias ou grandes. Quando comparadas as estruturas organizacionais de pequenas e médias organizações com as de grandes organizações, verificamse, normalmente, certas diferenças comuns em relação à liderança, burocracia, níveis de especialização e de formalização de atividades. As grandes organizações são usualmente mais burocráticas, com maiores níveis de especialização e normalização. Nas pequenas e médias organizações, por sua vez, são mais comuns relacionamentos informais e uma ausência de normalização, numa estrutura menos inchada, de poucas interfaces entre departamentos e forte influência da conduta administrativa do dirigente maior, muitas vezes o proprietário e fundador.

Price e Chen (1993), definem com o termo "maturidade" uma organização que desenvolveu a experiência e os sistemas necessários para a viabilidade do negócio a longo prazo. Segundo os autores, uma organização considerada "em desenvolvimento" se situa num estágio entre o início das atividades e a maturidade, período esse em que a organização deve estar se estruturando para suportar o seu crescimento. Ressalta-se, porém, que uma organização pode atingir a sua maturidade sem necessariamente tornar-se uma grande empresa. A transição de uma organização para o seu estágio de maturidade, envolve diversas mudanças de ordem organizacional e cultural. A geração, retenção e ampliação do conhecimento assume também importância significativa nessa transição.

Para as organizações recém-constituídas ou que evoluíram muito pouco, o produto ou serviço em si é visto como o foco principal do negócio. O ponto de vista centrado no produto ou serviço é gradualmente reduzido na transição da empresa para a maturidade, direcionandose para o mercado, para os processos, para ciclos de planejamento e melhorias.

As pequenas e médias organizações em estágio inicial de desenvolvimento, contam muito com contribuições individuais para atingir os seus resultados, advindas do conhecimento e experiência das pessoas. Os conhecimentos sobre as atividades ficam retidos na cabeça dessas pessoas e, em função disso, o conhecimento e a tecnologia dessas organizações podem ser perdidos com a saída das mesmas.

Com a evolução e o crescimento da organização, normalmente são criados departamentos que passam a ser responsáveis por determinadas funções. Esses departamentos necessitam de novas pessoas com conhecimentos para exercerem suas tarefas. O conhecimento, antes retido na cabeça de certas pessoas, passa a ser incorporado e compartilhado na organização, na medida em que, aos poucos, vão sendo estabelecidos novos processos e 
procedimentos. Grupos ou times de trabalho passam a substituir contribuições individuais, com a GQ e GC apresentando características mais evoluídas.

Garvin (2002), ao se referir aos movimentos da qualidade, afirma que "o centro de gravidade da disciplina desloca-se gradativamente para uma ênfase cada vez maior no gerenciamento", no entendimento de que a qualidade não é uma função isolada, realizada apenas por técnicos e especialistas. No Quadro 1, Garvin apresenta quatro estágios ou "eras" da qualidade, com as evoluções necessárias para se atingir o gerenciamento estratégico da qualidade.

A era de "Inspeção" (ou controle do produto ou serviço), corresponde a um enfoque de verificação da uniformidade do produto final e segregação das unidades não conformes. Para serviços, a verificação das condições de entrega dos mesmos.

A era de "Controle Estatístico da Qualidade" (ou controle do processo), segue a premissa de garantir a uniformidade do produto ou serviço com menos inspeção, num enfoque preventivo centrado no acompanhamento e controle de variáveis do processo que podem influir na qualidade final.

A era de "Garantia da Qualidade" apoia-se em programas e sistemas, que envolvem todos os departamentos associados à cadeia de produção ou serviços, no sentido de haver um planejamento da qualidade para impedir falhas e garantir a uniformidade do produto final. Muitas empresas que, por exemplo, implantaram um sistema da qualidade apoiado nas normas da série ISO 9000, sem um maior planejamento estratégico, encontram-se, provavelmente, somente nesse estágio evolutivo para com a qualidade.

O "Gerenciamento Estratégico da Qualidade", incorpora elementos de visão e planejamento estratégico das organizações no gerenciamento global dos negócios, com vistas às oportunidades diante da concorrência e à satisfação total do cliente.

Fleury (1993), ao analisar os processos de mudanças organizacionais provocados pela introdução inicial dos programas de qualidade e produtividade em empresas brasileiras, destaca as influências e resistências advindas de padrões culturais até então existentes nas organizações. Segundo a autora, "processos de mudança não ocorrem em uma única direção e podem sofrer avanços e retrocessos em função das crises externas e internas” (p.31).

No cenário atual, em meio ao dinamismo da globalização, o avanço de novas tecnologias, crises e re-estruturações em muitas organizações, reter e ampliar o conhecimento é crucial para não incorrer na repetição de erros e buscar diferenciais competitivos, mantendo a gestão da qualidade alinhada ao negócio e sua evolução. 


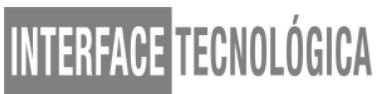

Quadro 1. As Quatro Principais Eras da Qualidade

\begin{tabular}{|c|c|c|c|c|}
\hline & \multicolumn{4}{|c|}{ Etapa do Movimento da Qualidade } \\
\hline $\begin{array}{l}\text { Identificação de } \\
\text { Características }\end{array}$ & Inspeção & $\begin{array}{l}\text { Controle Estatístico } \\
\text { da Qualidade }\end{array}$ & Garantia da Qualidade & $\begin{array}{l}\text { Gerenciamento } \\
\text { Estratégico da Qualidade }\end{array}$ \\
\hline $\begin{array}{l}\text { Preocupação } \\
\text { Básica }\end{array}$ & Verificação & Controle & Coordenação & Impacto Estratégico \\
\hline $\begin{array}{l}\text { Visão da } \\
\text { Qualidade }\end{array}$ & $\begin{array}{l}\text { Um problema a ser } \\
\text { resolvido }\end{array}$ & $\begin{array}{l}\text { Um problema a ser } \\
\text { resolvido }\end{array}$ & $\begin{array}{l}\text { Um problema a ser } \\
\text { resolvido, mas que seja } \\
\text { enfrentado de forma } \\
\text { proativa }\end{array}$ & $\begin{array}{l}\text { Uma oportunidade diante da } \\
\text { concorrência }\end{array}$ \\
\hline Ênfase & Uniformidade do produto & $\begin{array}{l}\text { Uniformidade do produto } \\
\text { (ou serviço) com menos } \\
\text { inspeção }\end{array}$ & $\begin{array}{l}\text { Toda a cadeia de produção, } \\
\text { desde o projeto até o } \\
\text { mercado, e a contribuição de } \\
\text { todos os grupos funcionais, } \\
\text { especialmente os projetistas, } \\
\text { para impedir falhas de } \\
\text { Qualidade }\end{array}$ & $\begin{array}{l}\text { As necessidades do mercado } \\
\text { e do consumidor }\end{array}$ \\
\hline Métodos & Instrumento de medição & $\begin{array}{l}\text { Instrumentos e técnicas } \\
\text { estatísticas }\end{array}$ & Programas e sistemas & $\begin{array}{l}\text { Planejamento estratégico, } \\
\text { estabelecimento de } \\
\text { objetivos e mobilização da } \\
\text { organização }\end{array}$ \\
\hline $\begin{array}{l}\text { Papel dos } \\
\text { profissionais da } \\
\text { Qualidade }\end{array}$ & $\begin{array}{l}\text { Inspeção, classificação, } \\
\text { contagem e avaliação }\end{array}$ & $\begin{array}{l}\text { Solução de problemas e a } \\
\text { aplicação de métodos } \\
\text { estatísticos }\end{array}$ & $\begin{array}{l}\text { Mensuração da Qualidade, } \\
\text { planejamento da Qualidade, } \\
\text { Projetos e Programas }\end{array}$ & $\begin{array}{l}\text { Estabelecimento de } \\
\text { objetivos, educação e } \\
\text { treinamento, trabalho } \\
\text { consultivo com outros } \\
\text { departamentos e } \\
\text { delineamento de programas }\end{array}$ \\
\hline $\begin{array}{l}\text { Quem é o } \\
\text { responsável pela } \\
\text { Qualidade }\end{array}$ & $\begin{array}{l}\text { O departamento de } \\
\text { inspeção }\end{array}$ & $\begin{array}{l}\text { Os departamentos de } \\
\text { produção e engenharia }\end{array}$ & $\begin{array}{l}\text { Todos os departamentos, } \\
\text { embora a alta gerência só se } \\
\text { envolva perifericamente } \\
\text { com o projeto, o } \\
\text { planejamento, a execução } \\
\text { das políticas da Qualidade }\end{array}$ & $\begin{array}{l}\text { Todos na empresa, com a } \\
\text { alta gerência exercendo } \\
\text { forte liderança }\end{array}$ \\
\hline $\begin{array}{l}\text { Orientação e } \\
\text { abordagem }\end{array}$ & "Inspecionar" a Qualidade & “Controlar" a Qualidade & "Construir" a Qualidade & “Gerenciar" a Qualidade \\
\hline
\end{tabular}

Fonte: Garvin (2002)

Toledo e Carpinetti (2000) descreveram tendências então vigentes em relação às práticas da gestão da qualidade no meio industrial, indicando uma gestão da qualidade mais dinâmica devido às mudanças nas exigências dos clientes, organismos reguladores da qualidade e o ritmo intenso das inovações tecnológicas.

Numa publicação da ASQ (2008), The American Society for Quality, foram indicadas sete forças de mudança que impulsionariam o futuro da gestão da qualidade, notadamente forças ou tendências externas à organização: 1) Globalização; 2) Responsabilidade Social; 3) Novas dimensões para a Qualidade; 4) Idade da população; 5) Cuidados com a saúde; 6) Preocupação Ambiental e 7) Tecnologia do século 21.

Quando um determinado produto ou serviço pode ser considerado obsoleto em poucos meses, não há muito tempo para erros, evidenciando a importância e a preocupação que as organizações devem ter para com a qualidade nas suas estratégias e os conhecimentos 


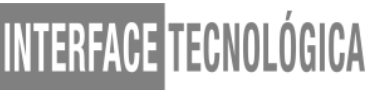

necessários envolvidos. Nesse contexto, surgem oportunidades a investigar de como o conhecimento dessas organizações e no mercado poderia ser melhor e devidamente utilizado, num sistema de GC delineado conjuntamente e em moldes similares aos vistos para a GQ.

A GC tem sido foco de muitos estudos em Administração, cuja importância é relacionada à fatores críticos de sucesso para as organizações. Possui um domínio multidisciplinar (ciências cognitivas, da informação, organizacionais e administrativas, e tecnologia da informação) e na administração, particularmente, possui uma forte ligação com mudanças, melhores práticas, reengenharia de processos de negócios e benchmarking (LIEBOWITZ, 1999).

Para se entender a GC, e em especial a teoria da criação do conhecimento, é importante analisar conceitos referentes às diferenças entre dados, informação e conhecimento, sendo este último constituído por dois formatos: o conhecimento tácito e o conhecimento explícito, existindo conversões entre ambos. Estas duas partes constituintes do conhecimento são tratadas por muitos pesquisadores, destacando-se os conceitos propostos por Nonaka e Takeuchi (1997), que apresentam esses formatos de conhecimento intrinsecamente relacionados:

- o formato TÁCITO: conhecimento subjetivo; habilidades inerentes a uma pessoa; atrelado à percepção e experiência; não formalizado e domuentado; mais difícil de ser transferido para outra pessoa;

- e o formato EXPLÍCITO: conhecimento relativamente fácil de codificar, transferir e reutilizar; formalizado em textos, gráficos, tabelas, figuras, desenhos, esquemas, diagramas, etc, facilmente organizados em bases de dados e em publicações em geral, tanto em papel como em formato eletrônico.

Uma Organização cria novos conhecimentos convertendo o conhecimento Tácito em conhecimento Explícito, e vice versa. Nonaka e Takeuchi (1997) propuseram um modelo explicativo desse processo de conversão, num ciclo composto por 4 modos ou etapas que se repetem contínua e indefinidamente, formando uma espiral, através do qual as organizações vão criando e ampliando o seu conhecimento: 1) Socialização: Compartilhar e criar conhecimento tácito através de experiência direta, de Indivíduo para Indivíduo; 2) Externalização: Articular o conhecimento tácito através do diálogo e da reflexão, de Indivíduo para Grupo; 3) Combinação: Sistematizar e aplicar o conhecimento explícito e a informação, de Grupo para Organização; 4) Internalização: Aprender e adquirir novo conhecimento tácito na prática, da Organização para Indivíduo. Na Etapa 2, a Externalização, acontecem as reuniões 
e debates de criação de soluções para os problemas, novos produtos e modos de operação, sendo essa etapa considerada como a mais importante, onde ocorrem as novas idéias e inovações.

Molina, Llórens-Montes e Ruiz-Moreno (2007) discutem em seu trabalho hipóteses de que o grau de implementação dos processos de qualidade, e respectiva GQ, está relacionado com a transferência do conhecimento interno e externo para a organização, influenciando positivamente os seus recursos e capabilidades, assim como sua vantagem competitiva.

A visão da qualidade e dos sistemas para a sua gestão evolui com o desenvolvimento organizacional. O Quadro 2, sintetiza uma comparação entre fases de evolução organizacional e a evolução dos enfoques clássicos em GQ e GC.

A maturidade dos processos internos de gestão deve estimular e agilizar os processos de inovação. Fernandes, Lourenço e Sila (2014) concluem em seu trabalho sobre a influência da GQ no desempenho inovador, que a prática de revisão contínua dos processos da organização fomenta melhores resultados em formas de manifestação das atividades inovadoras.

Quadro 2. Evolução da Organização vs Evolução da GQ vs Evolução da GC

\begin{tabular}{|c|c|c|c|c|}
\hline ESTÁGIO & ORGANIZAÇÃO & $\begin{array}{l}\text { FOCO DO } \\
\text { NEGÓCIO }\end{array}$ & $\begin{array}{l}\text { GESTÃO DA } \\
\text { QUALIDADE }\end{array}$ & $\begin{array}{c}\text { GESTÃO DO } \\
\text { CONHECIMENTO }\end{array}$ \\
\hline Iniciante & $\begin{array}{l}\text { Muitas funções ainda } \\
\text { não estabelecidas. }\end{array}$ & $\begin{array}{l}\text { Produção inicial dos } \\
\text { produtos ou serviços. }\end{array}$ & $\begin{array}{l}\text { Baixa prioridade } \\
\text { comparada à necessidade } \\
\text { de foco e expedição de } \\
\text { produtos e/ou entrega dos } \\
\text { serviços. }\end{array}$ & $\begin{array}{l}\text { Tácito } \\
\text { Socialização }\end{array}$ \\
\hline $\begin{array}{l}\text { Em } \\
\text { Desenvolvimento }\end{array}$ & $\begin{array}{l}\text { Funções estabelecidas, } \\
\text { porém pouco providas } \\
\text { de pessoas exercendo } \\
\text { funções específicas }\end{array}$ & $\begin{array}{l}\text { Produção adicional e de } \\
\text { novos produtos e/ou } \\
\text { serviços, com expansão } \\
\text { no mercado em que } \\
\text { atua. }\end{array}$ & $\begin{array}{l}\text { Implementações e adoções } \\
\text { iniciais. Mapeamento dos } \\
\text { fluxos do processo. } \\
\text { Monitoramento de } \\
\text { medições. Treinamentos. }\end{array}$ & $\begin{array}{l}\text { Tácito - Explícito } \\
\text { Socialização } \\
\text { Externalização } \\
\text { Combinação inicial }\end{array}$ \\
\hline $\begin{array}{l}\text { na } \\
\text { Maturidade }\end{array}$ & $\begin{array}{l}\text { Funções estabelecidas, } \\
\text { providas de pessoal e } \\
\text { experiência por funções. }\end{array}$ & $\begin{array}{l}\text { Manutenção do } \\
\text { mercado atual e } \\
\text { expansão para novos } \\
\text { mercados. }\end{array}$ & $\begin{array}{l}\text { Estabelecido e } \\
\text { implementado por áreas. } \\
\text { Foco no processo e } \\
\text { melhoria contínua. }\end{array}$ & $\begin{array}{l}\text { Tácito-Explícito-Tácito } \\
\text { Socialização } \\
\text { Combinação } \\
\text { Internalização }\end{array}$ \\
\hline
\end{tabular}

Fonte: adaptação do autor sobre o quadro original de Price e Chen (1993)

Nagano, Stefanovitz e Vick (2014) destacam dois pontos sobre os desafios relacionados aos processos de gestão da inovação: 1) Deficiências da sistematização processual, referindose à dificuldade em se coordenar e orquestrar diversas áreas, onde o desempenho em inovação depende da disciplina no fluxo das atividades necessárias e a má gestão provoca baixa capacidade de atrelar os esforços individuais e coletivos às metas; 2) O perfil da Liderança diante da inovação, seja pelo nível de envolvimento e patrocínio à inovação de produto, pela capacidade de influenciar decisões nas dimensões mercadológicas e tecnológicas ou mesmo 


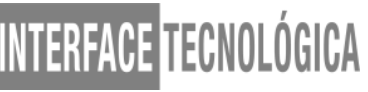

pela indução de padrões em questões como o nível de controle sobre o sistema e sobre os indivíduos.

Verifica-se que o papel dos gestores quanto à Liderança também é fundamental para a integração das diferentes gestões da organização. Em trabalho sobre a GC e o papel de uma "Liderança Autêntica", Besen, Tecchio e Fialho (2017) identificam alguns aspectos relevantes que podem contribuir para os processos de gestão quanto aos líderes envolvidos, basicamente: Forte caráter ético/moral; Autoconhecimento e estimular a autoconsciência dos seguidores; Alinhamento de suas ações e comportamento aos seus valores; Relações transparentes, criando ambientes de confiança; fomentar o desenvolvimento de seus seguidores.

Cherman e Rocha-Pinto (2016) também convergem sobre o papel da Liderança e a valoração do conhecimento nas organizações, indicando que "o contexto estrutural em que a organização se insere acaba por criar o contexto social e espacial que molda o padrão estruturante, estabelecendo a forma de pensar dos indivíduos acerca dos conhecimentos de valor e como agir para sua incorporação nas práticas e rotinas organizacionais".

Há uma relevância significativa na integração entre GQ e GC, onde a memória organizacional das práticas e resultados em qualidade, assim como a transmissão desse conhecimento, são também fatores críticos de sucesso para ações de evolução sobre a própria gestão e os resultados de inovação no negócio, importante para todas as organizações, e de extrema relevância para referência e uso por organizações iniciantes e pequenas e médias em desenvolvimento.

\section{ANÁLISE SOBRE OS RESULTADOS DESSA PESQUISA: GQ e GC em Ambientes Complexos de Atuação}

No momento atual, em que se incia a terceira década do novo milênio, além dos conceitos atrelados à satisfação dos clientes e à melhoria contínua dos produtos e serviços continuarem relevantes, novas tecnologias e conceios, como a Indústria 4.0, impulsionam a necessidade contínua de evolução da GQ e a sua interação com GC e processos de inovação. Há novos perfis e exigências dos clientes e consumidores, que com o avanço dos sistemas de informação e internet possuem o acesso fácil e rápido a dados sobre produtos e serviços, assim como fornecedores e respectivos desempenhos dos mesmos na percepção dos seus clientes para comparações, além de outros aspectos relacionados com a imagem das próprias organizações, 
relacionados com as suas preocupações éticas, de responsabilidade social e ambiental, divulgados na mídia e redes sociais via web, entre outras.

Estágios mais avançados e gradativos da GQ dependem da consolidação do estágio anterior, uso dos aprendizados e o conhecimento das novas necessidades para a evolução.

A Figura 1 sintetiza o escopo necessário da GQ e sua relação com a abrangência da GC e das novas tecnologias, no que se refere aos ambientes interno e externo de atuação da organização.

No ambiente interno, onde concentram-se os processos produtivos, a realização e entrega dos resultados esperados assumem uma característica de "Sistema Controlado", uma vez que a GQ planeja e controla padrões de execução e desempenho para assegurar a conformidade determinada. Há uma necessidade de "estabilidade" durante a execução e a própria norma ISO 9001 sobre sistemas de gestão da qualidade, na sua revisão recente em 2015, foca a necessidade da análise prévia e contínua dos riscos ao negócio que possam desviar o atendimento dos padrões estabelecidos, assim como monitorar o ambiente externo.

Figura 1. Escopo e interação da GQ, GC e novas tecnologias relacionado aos ambientes interno e externo de atuação da organização

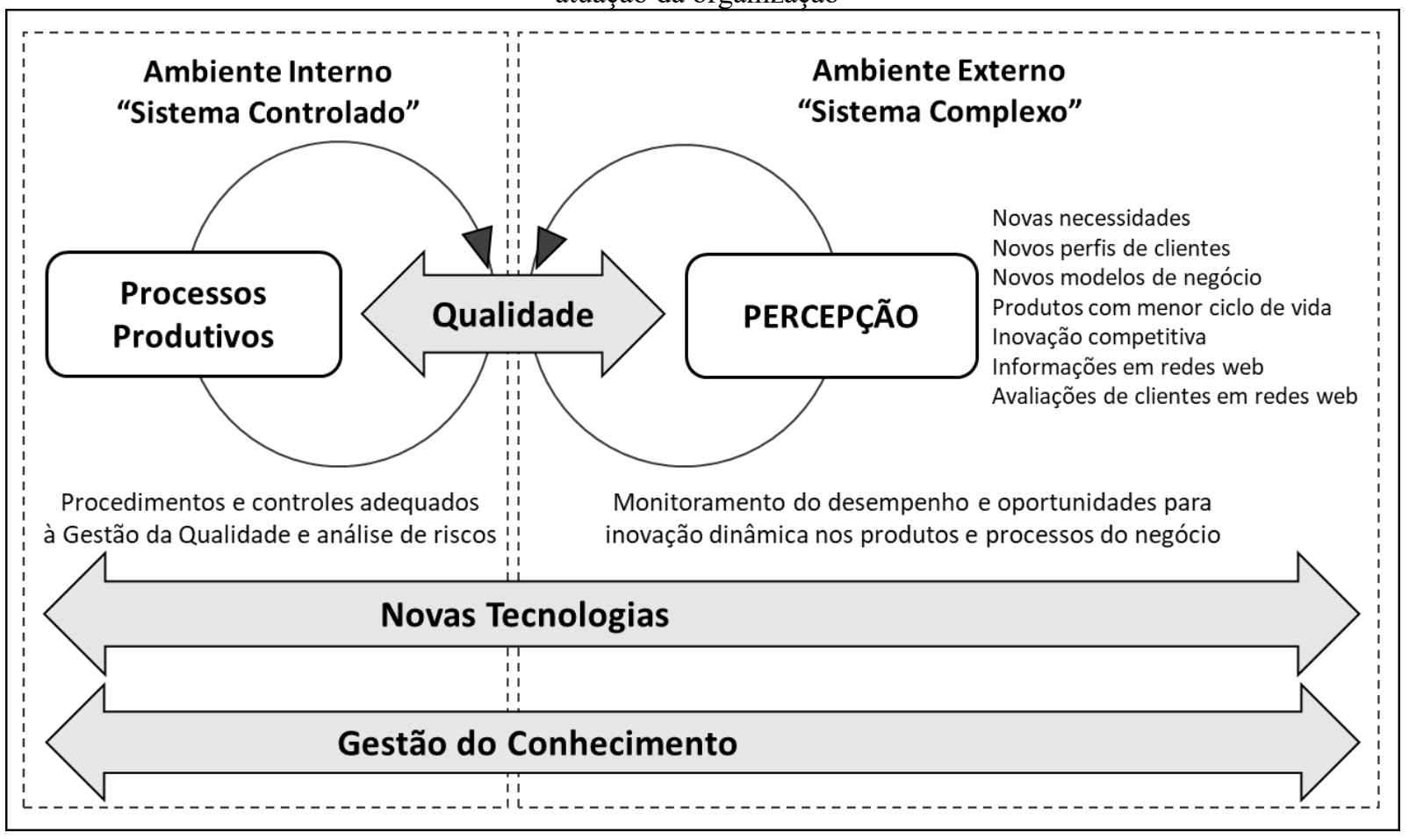

Fonte: Elaborado pelo autor. 


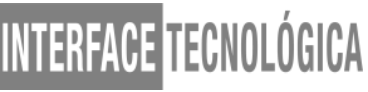

No ambiente externo, onde a organização atua e se depara com mudanças cada vez mais rápidas nos perfis dos respectivos mercados, clientes e consumidores finais do produto ou serviço, também cada vez mais atrelados ao impacto das novas tecnologias, verifica-se a aplicação dos conceitos sobre "Sistemas Complexos", composto por um grande número de agentes que interagem entre sí e com o meio constantemente, formando novas estruturas e comportamentos, gerando a necessidade de evolução e adaptação por todos os agentes.

A inovação, no contexto dos ambientes interno e externo das organizações, consite em fator de mudanças, gerando desenvolvimento e desbancando velhos paradigmas. A GQ, inserida no meio desses ambientes e atenta à percepção pelos clientes, incorporando de modo eficaz a GC, torna-se um fator chave para, de forma estruturada, entender, controlar, antecipar e fomentar oportunidades de inovação.

\section{CONSIDERAÇÕES FINAIS}

No contexto atual de forte globalização mundial e mercados interligados, sensíveis às crises políticas e econômicas, assim como o exemplo recente de crise provocada pela pandemia do coronavirus / COVID-19, além da alta competitividade, consumidores mais exigentes, informados e ávidos por novidades e agilidade nas operações, as organizações estabelecidas e consolidadas muitas vezes precisam se "reinventar", utilizando-se do melhor do seu conhecimento adquirido e da ampliação do mesmo, para atuar em ambientes caóticos e altamente evolutivos que as cercam.

As organizações iniciantes e as pequenas e médias, em desenvolvimento, precisam acelerar os seus processos internos para o rápido amadurecimento, consolidação e diferenciação no mercado. Para essas organizações, de um modo geral, a centralização do conhecimento em poucas pessoas, ou o conhecimento tácito elevado, pode representar uma armadilha quando de mudanças rápidas necessárias na organização.

Nos mercados de atuação que exigem maior dinamismo em mudanças estruturais, tecnológicas, desenvolvimento funcional, entre outras, a GQ e GC possuem relevância e contribuição significativa ao sucesso do negócio. Os gestores responsáveis por essas organizações devem estar atentos aos processos de evolução da GC, tendências e oportunidades com as novas tecnologias, assim como estimular nos indivíduos e equipes atividades criadoras de conhecimento organizacional e inovações, assim como minimizar barreiras pessoais quanto 
às mudanças cada vez mais rápidas necessárias, o que envolve preprarar e treinar os profissionais para que desempenhem novas funções.

O melhor desempenho em inovação e a superação de dificuldades comuns em GQ e $\mathrm{GC}$, indicam temas relevantes e sempre atuais para novas pesquisas, diante de contínuas novas demandas para as organizações. Aos gestores, cabe o papel relevante na liderança e atenção para com o tema e estágios evolutivos. Aos pesquisadores, o trabalho incansável de prospectar, avaliar e sistematizar possíveis novas formas de entendimento e modelos de referências para suporte e maior competitividade às empresas na era digital e de nova revolução industrial.

\section{REFERÊNCIAS}

ASQ 2008 FUTURES STUDY, The Seven Forces of Change Shaping the Future of Quality, The American Society for Quality, 2008, www.asq.org/knowledge-center/2008-futures-study.

CHERMAN, A.; ROCHA-PINTO, S. R. Valoração do conhecimento nas organizações e sua incorporação nas práticas e rotinas organizacionais, Revista Brasileira de Gestão de Negócios, São Paulo, v. 18, n. 61, p. 416-435 jul./set. 2016.

BESEN, F.; TECCHIO, E.; FIALHO, F. A. P. Liderança autêntica e a gestão do conhecimento, Revista Gestão \& Produção, São Carlos, v. 24, n. 1, p. 2-14, 2017.

FERNANDES, A. A. C. M.; LOURENÇO, L. A. N.; SILA, M. J. A. M.; Influência da Gestão da Qualidade no Desempenho Inovador, Revista Brasileira de Gestão de Negócios, São Paulo, v. 16, n. 53, p. 575-593, out./dez. 2014.

FLEURY, M. T. L. Cultura da Qualidade e Mudança Organizacional, Revista de Administração de Empresas, São Paulo, pp. 26-34, Mar/Abr 1993.

GARVIN, D. A. Gerenciando a Qualidade: A Visão Estratégica e Competitiva, Qualitymark Editora, Rio de Janeiro, 2002.

LIEBOWITZ, J., Knowledge Management Handbook. CRC Press., 1999.

MOLINA, L. M.; Llórens-Montes, J.; Ruiz-Moreno A. Relationship between quality management practices and knowledge transfer, Journal of Operations Management, n. 25, p. 682-701, 2007.

NAGANO, M. S.; STEFANOVITZ, J. P.; VICK, T. E. Caracterização de Processos e Desafios de Empresas Industriais Brasileiras na Gestão da Inovação, Revista Brasileira de Gestão de Negócios, Neg., São Paulo, v. 16, n. 51, p. 163-179, abr./jun. 2014.

NONAKA, I.; TAKEUCHI, H., Criação de conhecimento na empresa. Rio de Janeiro, Campus, 1997.

PRICE, M. J., CHEN, E. E. Total Quality Management in a Small, High-Technology Company, California Management Review, pp. 96-117, spring 1993.

TOLEDO, J. C., CARPINETTI, L. C. R. Gestão da Qualidade, Fábrica do Futuro: Entenda hoje como sua indústria vai ser amanhã, edição especial publicada pela Editora Banas, pp. 115-122, Dez 2000. 